\title{
TREATMENT IN LEPROSY WITH ETISUL PRELIMINARY INFORMATION
}

\author{
by Doctors V. K. Loginov, N. G. Vantanova and V. S. Bragina
}

(Reprinted from Ucheniye Zapiski No. 3/8, Astrakhan 1962, pp. 9-14, in English translation from the original Russian by the kindness of Dr. J. I. Mirilow of Medical Department, Imperial Chemical Industries Ltd., Macclesfield, Cheshire, England).

Del Pianto has established (1950) that a mixture of different thiols contains material capable of preventing development in experimental tuberculosis in guinea pigs. That information has attracted the attention of research workers towards a combination of thiols and towards the possibility of obtaining a remedy against tuberculosis. Davies et al. (1956) discovered that anti-tubercular action was inherent only in the ethyl homologous substances containing a mercaptan combination. Further research carried out by Davies and Driver (1958) has proved that Etisul has that antitubercular action which was comparable with the actions of isoniazide and streptomycin.

Mercaptan is a colourless, volatile liquid with an unpleasant odour. Chemically it is very similar to alcohol, differing from them in their sensitivity to oxidate. Etisul is an ester of isophthalic acid and ethyl mercaptan. This pale coloured oily liquid has an odour reminiscent of garlic and of decaying fruit.

The first thiol substance (sodium ethyl thiosulphate) for the medical treatment of leprosy patients was investigated by BERTACCINI in 1957. These observations were carried out on 31 patients with symptoms of leprosy ( 26 men patients with lesions were treated with sulpha drugs). Only 14 of these patients had active manifestations of the disease for the following 9 months. The authors found that the drug had a definite action in the treatment of leprosy, no less than certain other remedies.

DAVEY (1958) has observed that an application of Etisul on the skin by inunction (rubbing) brought about a quick and significant reduction of bacterioscopic index. Degenerative signs of Mycobacterium leprae have been noticed after 3 weeks of its application. Del Pianto himself came to the same conclusions in 1958.

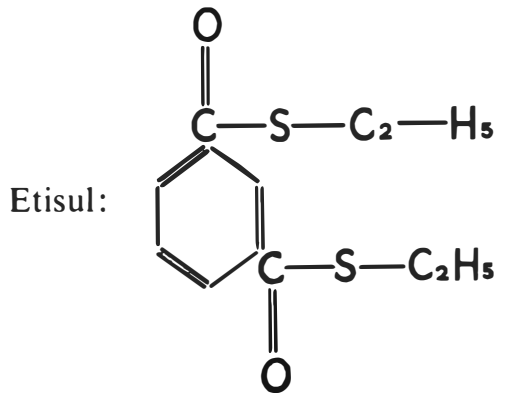


Davey and Hogerzell in 1959 published their results after 19 months of clinical trials on 65 patients who had active manifestations of leprosy and were treated with Etisul. They came to the conclusion that Etisul displayed a visible chemotherapeutic action in the first two to three months of treatment. So the treatment continued. But on exceeding four months of treatment there were signs of $M y c o-$ bacterium leprae resistance to the treatment observed in these patients. The authors noticed that if, after 8-12 weeks of treatment, they added to the Etisul DDS (Ciba 1906) or DDSO, the effect of treatment would be more noticeable. DaveY and HogerzeIL wrote that after one year of such treatment there were regressive changes for at least six months, surpassing such cases where only the treatment with the conventional preparations was administered internally They personally recommended the application of Etisul in combination with DDS.

Six months after publication of his first results DAvEY (1959) published his further observations and came to the conclusion that the best effects had been observed when Etisul was given in conjunction with DDS and DPT (Ciba 1906).

During the past two years a number of publications have appeared, the authors confirming the positive influence of Etisul on the course of a leprosy process. (LeChat, 1959; Ross, Telfer and Hilton 1960; Ross InNes, 1960; Browne, 1960; MukerJeE and Ghosal, 1960; Molesworth, 1961; Jamison, 1961; Dharmendra and NoRdeEN, 1961).

At that time (1961) Davison had applied Etisul in conjunction with DPT and DDS in 33 cases of leprosy during a period of 12 months and the results were identical with the results obtained in 33 patients treated only with DPT and DDS. He did not notice any real difference in therapeutic effect.

We had under our care 10 patients. They were suffering from the lepromatous type of leprosy and they were all treated at the Institute for the Study of Leprosy in 1961 (Dr. Subin's Institute at Astrakhan, U.S.S.R.) and until that time none of them had any treatment for the above mentioned complaint. In the age group between 17 to 20 years there were 3 patients, in the age group 21 to 30 years there were 4 patients, in the age group 41 to 50 years, 2 patients but in the age group over 50 there was only one patient. There were 4 male and 6 female patients. In all patients the leprosy process developed in an active form and was in a rather advanced stage. The manifestations of the skin were focal infiltrations, deep and diffused infiltrations and nodules. In four of those patients, because of the infiltrations which affected the mucosa of the upper respiratory tract and the muco-membranes of the nose, the respiration was impaired. One patient suffered from aphonia. Six patients were treated and cured where the process was affecting the peripheral nervous trunk. 
They had a severe pain on palpation and a local temperature of the extremities. Six patients were treated simultaneously, the others according to the order of their admission to the Institute. Portions of skin were taken from the affected parts of the body for the purpose of histological examination. The lepromatous structure of the infiltrations was confirmed and contained a large number of $M$. leprae which were mainly homogeneous.

We applied the following method of treatment. Etisul was obtained in the form of a cream from I.C.I. Limited, at $5 \mathrm{~g}$. and it was given to the patients twice a week by inuncting. The inunction was made both to the apparently unaffected parts of the body as well as those parts of the body which had nodules, but excluding the head, neck and hairy parts. At first the treatment of inunction was done by the nursing Sister, but as time went on the procedure was carried out by the patients themselves under Sister's supervision. The procedure of inunction lasted about 20 minutes. After that followed an hour's rest; at the time of rest the parts of affected and inuncted skin were left uncovered. Some time after the patients had a shower. The cream was rubbed into the skin, alternately the shoulders, chest, abdomen, along the spine, buttocks and hips. The disposition of the diseased lesions was not taken into account at this stage. Each of these patients received 'Avlosulfon' (DDS) by mouth; $100 \mathrm{gm}$. daily for the duration of 4 weeks. At the beginning of the fifth week the dose of 'Avlosulfon' was increased to $200 \mathrm{gm}$. daily, $100 \mathrm{~g}$. morning and $100 \mathrm{~g}$. evening. All these patients treated with Etisul were housed in a separate building. The unpleasant garlic odour due to Etisul did not worry the patients although its smell lingered persistently.

The course of treatment lasted six months. During that time the patients received 22 inunctions of Etisul and $28.2 \mathrm{~g}$. of 'Avlosulfon' per month. On completion of the first course of treatment with Etisul and 'Avlosulfon' the six remaining patients received from 23 to 40 inunctions of Etisul and an adequate quantity of 'Avlosulfon'. As a result of treatment there was constant regression of the disease. It was noticed in all patients that there was a disappearance of infiltrations and nodules and reduction and complete disappearance of facial swellings and puffiness. Breathing through the nose became easier and freer and recovery of the voice set in. Worsening of the affected peripheral nervous system was not noticed in any patient.

Histological examination of the affected portions of the skin has been followed in six cases. In all these patients we were in a position to establish changes such as the appearance of regression in specific symptoms, infiltrations of the skin becoming much more limited, fibrous changes occurring and also a reduction in the number of $M$. leprae which became predominantly granular. In one case the infiltration of lepromatous structures was replaced by an infiltration 
of the type of a simple inflammation with isolated granular M. leprae.

Marked improvement in general state of health was noticed, for the patients gained approximately 2 to $3 \mathrm{~kg}$. in weight.

Symptoms of toxic dermatitis appeared in two cases in the course of treatment. Thus we had to stop the treatment temporarily, but after the symptoms of toxic dermatitis disappeared the treatment was resumed. In these two cases the dosage was reduced. One of these patients abandoned the double dose cycle. In two cases albumin was detected (0.099 mgm. per cent. and $0.165 \mathrm{mgm}$. per cent). The albumin disappeared during the course of treatment. In three cases sedimentation was slowed down. In three other cases on examination the bacterioscopic index was reduced to 0 . At the same time, in five patients despite the dosage with vitamin B12, we noticed a depressing influence on the blood state. They had reduced haemoglobin by 1.4-1.7 g. per cent. and erythrocytes by $1-1.2$ million. For illustration we shall give you short notes about the history of the disease on all those patients who are still under observation.

\section{Case 1}

\section{Patient Z}

(Female), 26 years old. Entered the Institute for the Study of Leprosy on 20th April 1961 with lepromatous type of leprosy showing an erythematous infiltration on her face, neck and upper and lower extremities. These infiltrations were diffused on both buttocks and rather superficial. In the region of the hips the infiltration was much more marked. At the elbow the cubital and ulnar nerves were moderately thickened on palpation. The lepromin test was negative. On histological examination a portion of the diseased skin showed an infiltration of lepromatous type which was observed together with a quantity of homogeneous leprosy bacilli. On the 8th May 1961 treatment started with 'Etisul' by inunction and 'Avlosulfon'. Regressive changes were observed after 5 inunctions with Etisul; loss of brightness in colour of the infiltrations, both on the patients face and on the extremities was noted. At the same time the patient had an abortion performed by a doctor which terminated her six weeks' pregnancy. As the treatment continued the regression of this patient's infiltrations progressed favourably. After 10-12 inunctions with Etisul there was a definite improvement for the infiltrations of the face became paler and on the extremities the infiltrations acquired rather a yellowish brownish colour. The infiltrations in other parts of the body began to decrease and gradually the facial infiltrations almost disappeared towards the end of the treatment. The infiltrations of the extremities disappeared as well; but on the skin around the hips pronounced infiltrations were noted at the beginning of treatment and patches of hyperchromia appeared. On repeating the histological examination 
of the diseased skin (after the completion of treatment), regressive changes had taken place. There was a sort of replacement of infiltrations of the lepromatous type with homogeneous $M$. leprae by insignificant infiltrations with simple inflamed structure and an isolated granular mycobacterium. At the same time there was noticed a development of fibrous changes.

At the end of treatment the bacterioscopic index became equal to $0(42.5 \%$ before the beginning of treatment $)$. It was also noticed that previous to the course of treatment with Etisul and Avlosulfon albumin was present in approximately $0.165 \%$ but it disappeared at the end of treatment.

Erythrocytes which were at the beginning of treatment approximately 4,210,000 went down to $2,650,000$ after the treatment was completed.

\section{Case 2}

\section{Patient G}

(Male), 20 years of age. Admitted to the Institute for the Study of Leprosy on 20th April 1961 with lepromatous type of leprosy. There were deep infiltrations present on his face, uneven infiltrations on the hands, and in places confluent lesions erythematous in colour and single nodules. On the skin of the chest, abdomen and along the spine marked infiltrations were present of a rosy red colour. The infiltrations were also present in the patient's lumbar region and they were slightly swollen. On palpation it was found that the elbow nerves were moderately thickened and diseased. The lepromin reaction was negative. On histological examination a portion of the skin was found to possess signs of lepromatous infiltration, together with a large quantity of homogeneous and granular bacilli. The treatment with Etisul and Avlosulfon began on 8th May 1961. After five inunctions with Etisul it was noticed that swollen infiltrations in the lumbar region became somewhat paler and less swollen. As the treatment went on it was observed that the infiltrations became gradually paler and resorption of the infiltrations took place on the face, lumbar region and extremities.

After 40 inunctions with Etisul it was observed that the fluid exudate regressed. There were noticeable reductions in infiltrations of the face and extremities. As far as the lumbar region is concerned, the infiltrations have almost disappeared. Once the course of treatment was completed there were only residual manifestations in the facial infiltrations. The original infiltrations which appeared in the lumbar region began to look macular. On histological examination which was repeated on a number of occasions it was found that changes had taken place in decreasing the infiltrations and there was an increase in granular forms of mycobacteria. 


\section{Case 3}

\section{Patient D}

(Male), 17 years of age. Admitted to the Institute for the Study of Leprosy on 14th March 1961, with a rather large part of his body affected by the lepromatous type of leprosy. There were diffused infiltrations on the face, especially of external audiotory meatus and the ear lobe. Breathing through the nose was rather difficult and there was aphonia. Vast and deep infiltrations were situated on the chest and the abdomen. There were diffused infiltrations on the extremities. On both elbows the nerves were swollen. There was also disturbing pain of the polyneuritic type around the elbow and the knee joint.

The lepromin test was negative. On histological examination of the diseased portions of skin, structures of the lepromatous type were observed and also a large quantity of homogeneous and granular leprosy bacilli were seen. Thus the treatment began on the 8th May 1961 with inunction of Etisul, and Avlosulfon by mouth. After 5 inunctions of Etisul the patient's voice became clearer, more sonorous. Later the colour of the patient's face became paler, the infiltration regressed. Breathing through the nose became free. After 35 treatments with Etisul and 105 treatments with Avlosulfon the patient's voice became normal, the infiltrations on the face decreased, while the infiltrations on the back disappeared. At the end of treatment there was a noticeable decrease in the infiltrating process. The general condition of the patient as far as health goes during the treatment was good. His weight went up by $11 \mathrm{~kg}$.

Aggravation in the process of the disease was not observed. By repeating histological examination regressive changes were noted which were expressed in reduction of infiltrations in the area and degeneration in the mycobacteria. Before treatment $0.099 \mathrm{mgm}$. per cent of albumin was found in the patient's urine and it disappeared altogether after 22 inunctions with Etisul.

We have carried out a comparative appraisal of the results of treatment by Etisul in combination with Avlosulfon (DDS) compared with the results obtained in treatment of the patients with DDS alone. Our preliminary observations allowed us to suppose that by application of Etisul in combination with Avlosulfon regressive changes in the cutaneous symptoms became more evident, and much earlier evident. So towards the end of the course of treatment the results were more permanent than in the patients where the treatment was carried out by Avlosulfon only.

In the groups of patients treated with Etisul and Avlosulfon there was evidence that one patient's treatment was aggravated by the combination of Etisul and Avlosulfon. In no case did we notice any reaction on the skin. In the patients who were treated with Avlosulfon only some reactions of nodular erythema were seen. 


\section{Summary}

(a) Combined therapy of Etisul and Avlosulfon on patients with lepromatous type of leprosy who were not previously treated showed a rapid effect from the clinical point of view which was confirmed by histological examination.

(b) In some patients, in the process of treatment with Etisul and Avlosulfon it was possible to observe a depression in the function of the haempoietic system which is connected to some extent with the action of Avlosulfon.

(c) The foregoing observations on the action of Etisul and Avlosulfon on all types of leprosy ought to be continued and similarly the use of Etisul in combination with DPT should be tested.

\section{References}

Bertaccini, G. Min. Dermatol., 1957, v. 32, No. 1, p. 22.

Browne, S. G. Lep. Rev. 1960, v. 31, No. 2, p. 83.

DaVEY, T. F. Trans. of the VII Int. Con. of Leprology, Tokyo, 1958, p. 252.

DaveY, T. F. Lep. Rev., 1959, v. 30, No. 3, p. 141.

Davey, T. F., Hogerzeil, L. M. Lep. Rev. 1959, v. 30, No. 1, p. 61.

Davies, G. E., Driver, G. W., Huggarti, E., Martin, A. R., Paige, M., ROSE, E., WILSON, B. Brit.J. Pharmacol. a. Chemotherapy, 1956, v. 11, p. 351. Davies, G., Driver, G. Nature, 1958, v. 182, p. 664.

Davison, A. R. Lep. Rev. 1961, v. 32, No. 1, p. 40.

Dharmendra, NoORdeEn, S. K. Intern. J. of Lep. 1961, v. 29, No. 1, p. 34.

Jamison, D. G., Palmer, E., Vollum, R. L. Trans. Roy. Soc. Trop. Med. Hyg. 1961 , v. 55 , No. 2 , p. 142.

Lechat, M. F. Ann. Soc. Belg. Med. Trop. 1959, v. 39, No. 6, p. 865.

McGregor, H. Lep. Rev. 1961, v. 32, No. 1, p. 36.

Molesworth, B. D. Lep. Rev. 1961, v. 32, No. 3, p. 150.

MukerJee, N., Ghosal, P. Lep. in India, 1960, v. 32, No. 1, p. 10.

PiANTO, E. Ric. Scient. 1950 , v. 20 , p. 83.

Pianto, E. Trans. of the VII Int. Congress of Lep. Tokyo, 1958, p. 279.

Ross INNES, J. Lep. in India, 1960, v. 32, No. 1, p. 9.

Ross, C. M., Telfer, J. F., Hilton, D. D. Lep. Rev. 1960, v. 31, No. 4, p. 260.

Thangaraj, R. H., ThangaraJ, S. Antiseptic, 1961, v. 58, No. 3, p. 179. 